Supporting Information

\title{
Continuous fabrication of antimicrobial nanofiber mats using post-electrospinning functionalization for roll-to-roll scale-up
}

Keke Chen, ${ }^{a}$ Shantanu P. Nikam, ${ }^{\mathrm{b}}$ Zachary K. Zander, ${ }^{\mathrm{b}}$ Yen-Hao Hsu, ${ }^{\mathrm{b}}$ Nathan Z. Dreger,

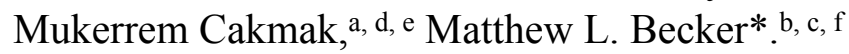

${ }^{a}$ Department of Polymer Engineering, University of Akron, Akron, OH 44325, United States

${ }^{b}$ Department of Polymer Science, University of Akron, Akron, OH 44325, United States

${ }^{c}$ Department of Biomedical Engineering, University of Akron, Akron, OH 44325, United States

d School of Materials Engineering, Purdue University, West Lafayette, IN 47907, United States

e School of Mechanical Engineering, Purdue University, West Lafayette, IN 47907, United States

${ }^{\mathrm{f}}$ Department of Chemistry, Mechanical Engineering and Materials Science, and Orthopaedic Surgery, Duke University, Durham, NC, 27708, United States

\section{Author Information:}

Corresponding Author:*E-mail: matthew.1.becker@duke.edu

\section{CONTENTS}

Scheme S1: allyl-TPU synthesis

Scheme S2: QAC-OH synthesis

Scheme S3: 3,3'-dithiopropanoyl chloride synthesis

Scheme S4: QAC-S-S synthesis

Scheme S5: QAC-SH synthesis

Scheme S6: Rhodamine-SH synthetic route

Scheme S7: LAP synthesis

Figure S1: ${ }^{1} \mathrm{H}-\mathrm{NMR}$ spectra of allyl-TPU

Figure S2: SEM images of the allyl-TPU fiber mats at all investigated conditions: electrospun fibers from $3 \%, 5 \%, 8 \%, 10 \%, 12 \%$ and $15 \% \mathrm{w} / \mathrm{v}$ allyl-TPU in 50/50 v/v DMF/THF cosolvent at $8 \mathrm{~cm}, 12 \mathrm{~cm}, 16 \mathrm{~cm}$, and $20 \mathrm{~cm}$ TDs.

Figure S3: SEM image of the allyl-TPU fiber mats from $1 \%$ allyl-TPU in 50/50 v/v DMF/THF cosolvent at $8 \mathrm{~cm}$ TD.

Figure S4: Viscosity plot as a function of shear rate for allyl-TPU solution in $50 / 50 \mathrm{v} / \mathrm{v}$ $\mathrm{DMF} / \mathrm{THF}$ cosolvent at various concentrations. 
Figure S5. Dependence of fiber diameter on the specific viscosity of allyl-TPU solution.

Figure S6: Cross-sectional SEM images of the allyl-TPU fiber mats electrospun at a concentration of $10 \% \mathrm{w} / \mathrm{v}$ and TDs of (A) $10 \mathrm{~cm},(\mathrm{~B}) 12 \mathrm{~cm}$, and (C) $16 \mathrm{~cm}$.

Figure S7: Additional diffusion assay images of UV-treated, physically adsorbed and untreated samples.

Figure S8: Images from the live/dead assay for untreated, physically adsorbed and UV-treated allyl-TPU fiber mats after in contact with S. aureus (top) and E. coli (bottom) for $15 \mathrm{~min}$.

Table S1. Summary of the characteristics of allyl-TPUs.

Table S2. Summary of electrospun TPU fiber diameters derived at different concentrations and TDs.

Table S3. Mechanical properties of the allyl-TPU fiber mats electrospun at a concentration of $10 \% \mathrm{w} / \mathrm{v}$ and TDs of $10 \mathrm{~cm}, 12 \mathrm{~cm}$, and $16 \mathrm{~cm}$.

Table S4. Quantification of rhodamine-SH and QAC-SH present on UV treated and physically adsorbed allyl-TPU fiber mats as determined by fluorescence spectroscopy and XPS measurements, respectively.

Table S5. Contact-killing assay (adapted from ISO 22196) results of UV-treated, physically adsorbed and untreated allyl-TPU fiber mats in contact with E. coli and $S$. aureus suspensions (ca. $10^{5} \mathrm{CFU} / \mathrm{mL}$ ) for $24 \mathrm{~h}$.

Table S6. Comparing mechanical properties of fiber mats before and after functionalization.

Section S1. Derivation of Equation (1). 


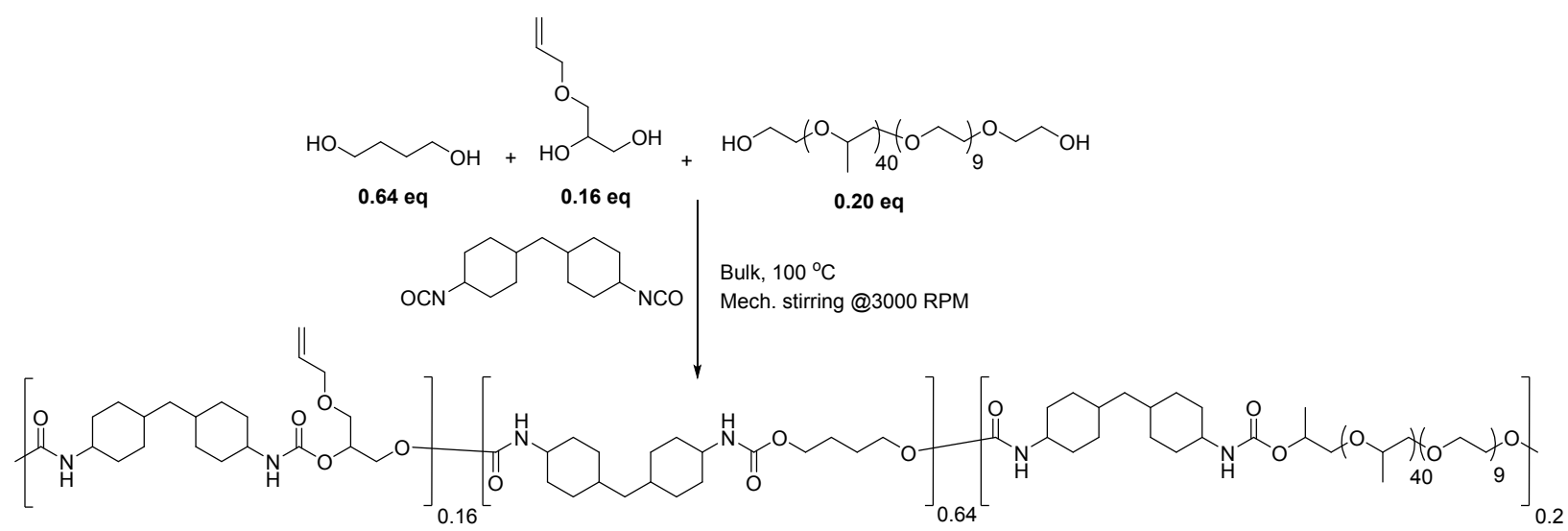

Scheme S1. Synthetic scheme for the polyurethane copolymers with allyl ether side functionality (allyl-TPUs). The molar composition as determined by ${ }^{1} \mathrm{H}$ NMR was found to be HMDI:AcrolE351:BDO:allyloxy-propanediol = 0.5:0.1:0.32:0.08 (Figure S1).<smiles>CCC(C)N(C)CCC(C)O</smiles>

Scheme S2. The QAC compounds (QAC-OH) were produced via neat quaternization reactions of DTDA with 8-chloro-1-octanol.<smiles>O=C(O)CCSSCCC(=O)O</smiles>

Scheme S3. 3,3'-dithiopropanoyl chloride was synthesized by reacting 3,3'-dithiopropionic acid with excess thionyl chloride under overnight reflux.<smiles>CC(C)CCCC(=O)OC(=O)CCSSCCC(=O)Cl</smiles>

Scheme S4. The QAC disulfide reagent (QAC-S-S) was synthesized by esterification of the corresponding $\mathrm{Q} x$-OH compounds with 3,3'-dithiopropanoyl chloride. 


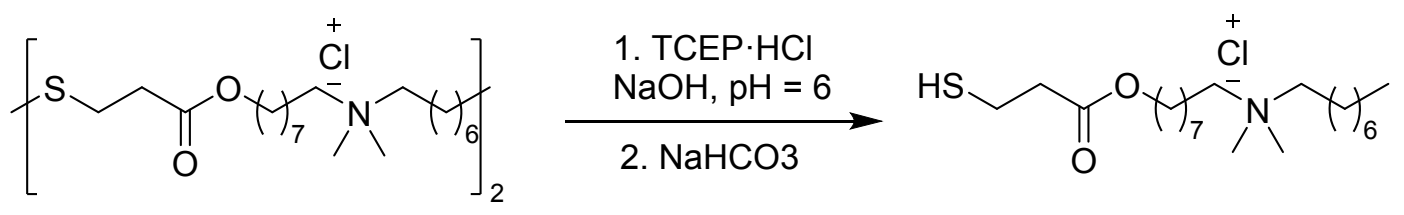

Scheme S5. The Quaternary ammonium thiol (QAC-SH) was synthesized by reduction of a QAC disulfide precursor with tris(2-carboxyethyl)phosphine (TCEP).<smiles>CCN(CC)c1ccc2c(-c3ccccc3C(=O)O)c3ccc(=[N+]([O-])CC)cc-3oc2c1</smiles>

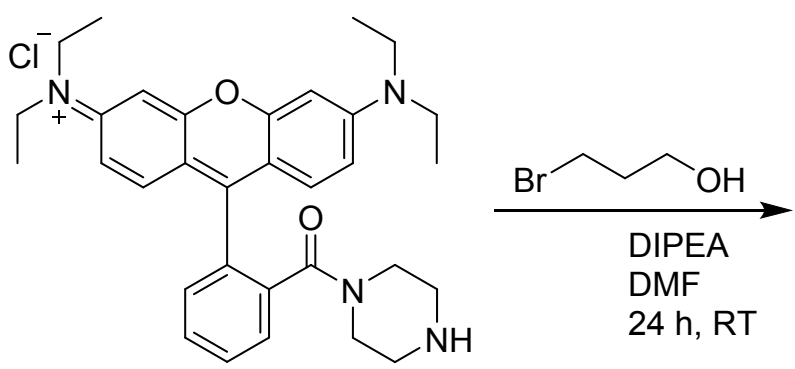<smiles></smiles><smiles>CCN(CC)c1ccc2c(-c3ccccc3C(=O)N3CCN(CCCOC(=O)CCSC(C)(C)C)CC3)c3ccc(=[N+](CC)CC)cc-3oc2c1</smiles><smiles>CCN(CC)c1ccc2c(-c3ccccc3C(=O)N3CCN(CCCOC(=O)CCS)CC3)c3ccc(=[N+](CC)CC)cc-3oc2c1</smiles>

Scheme S6. Rhodamine-SH synthetic scheme beginning with the formation of the lactone, amidation with piperazine, nucleophilic substitution of 3-bromo-1-propanol, esterification with 3,3'-dithiopropanoyl chloride, and reduction to thiol using TCEP. 
<smiles>COP(OC)c1ccccc1</smiles>

Scheme S7. Lithium phenyl-2,4,6-trimethylbenzoylphosphinate (LAP) photoinitiator was synthesized using a Michaelis-Arbuzov reaction between the acid chloride and alkyl phosphonite to generate the acyl phosphinate, followed by treatment with $\mathrm{LiBr}$.
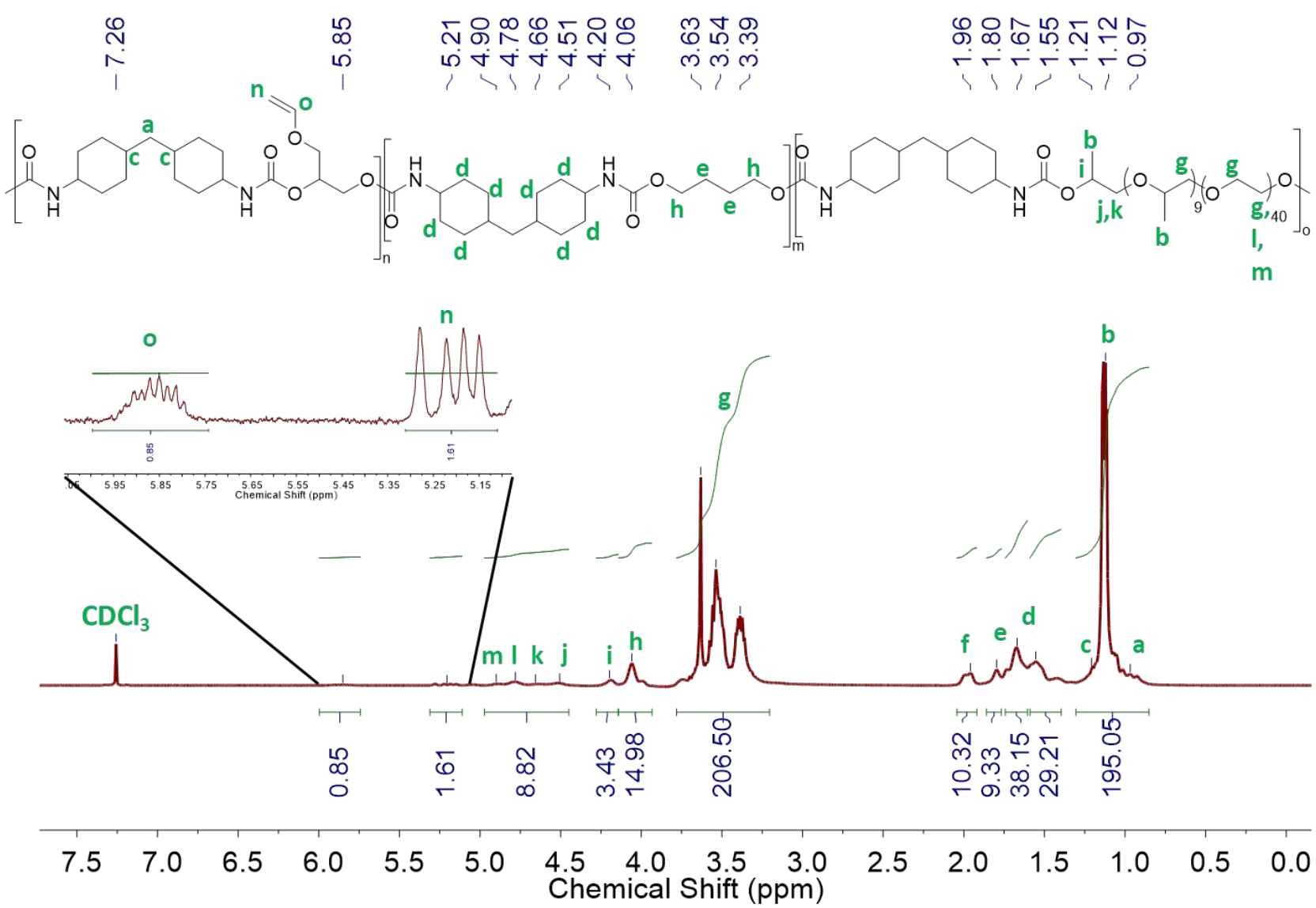

Figure S1. ${ }^{1} \mathrm{H}-\mathrm{NMR}$ spectra of the polyurethane copolymers with the allyl ether side functionalities (allyl-TPU). Peak $n$ and peak o correspond to the allyl group from 3-allyloxy-1,2propanediol units in allyl-TPU. The molar ratio of allyl functionalities was determined by peak integration and to be $\sim 8.1 \mathrm{~mol} \%$. Peak $\mathrm{g}$ and peak b confirmed the presence of Arcol E-351; peak $\mathrm{e}$ and peak $\mathrm{h}$ correspond to the alkyl chains in 1,4-butanediol units. The molar composition as determined by ${ }^{1} \mathrm{H}$ NMR was found to be HMDI:Acrol-E351:BDO:allyloxy-propanediol = 0.5:0.1:0.32:0.08. 


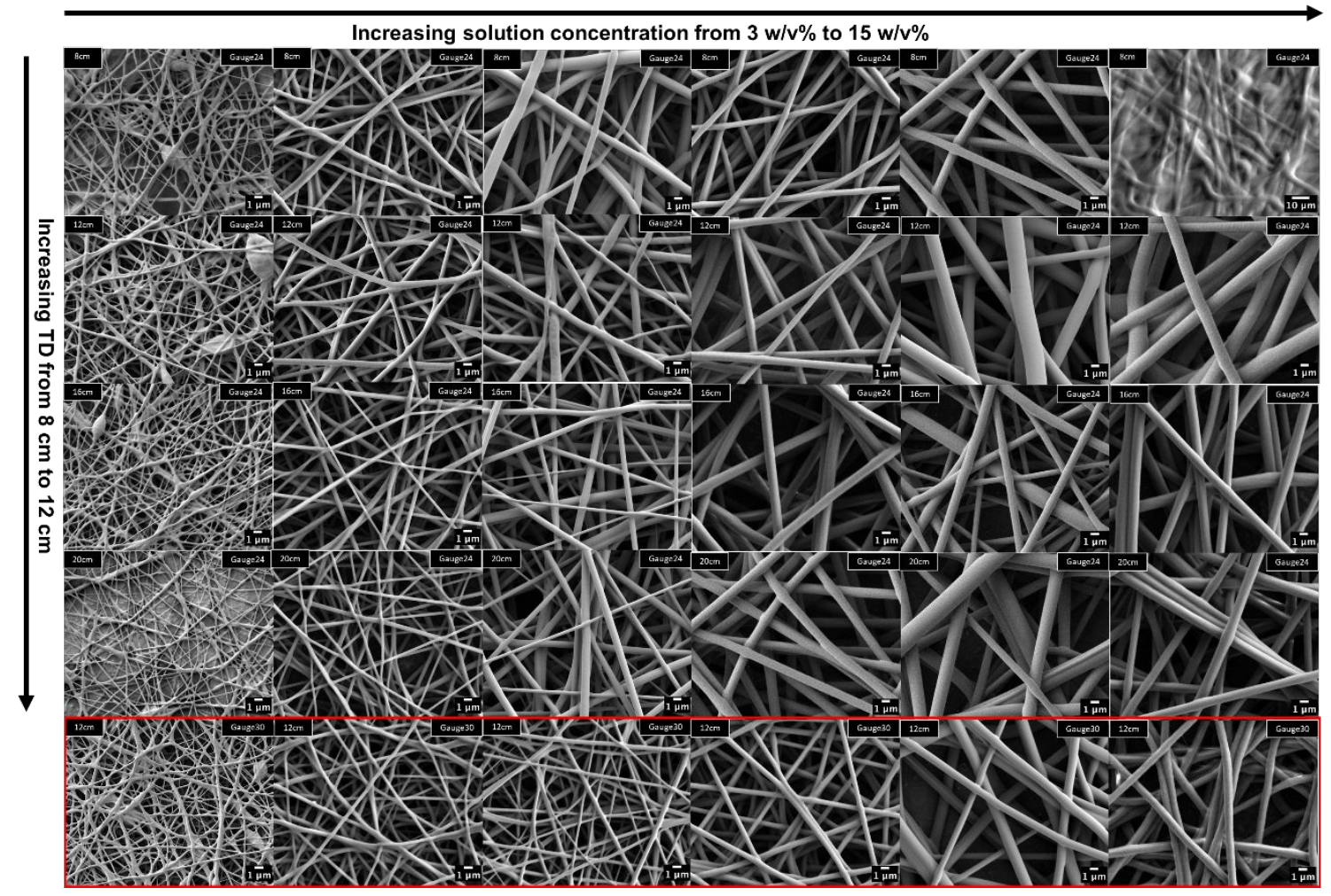

Figure S2. SEM images of the allyl-TPU fiber mats at all investigated conditions: electrospun fibers from $3 \%, 5 \%, 8 \%, 10 \%, 12 \%$ and $15 \% \mathrm{w} / \mathrm{v}$ allyl-TPU in 50/50 v/v DMF/THF cosolvent at $8 \mathrm{~cm}, 12 \mathrm{~cm}, 16 \mathrm{~cm}$, and $20 \mathrm{~cm}$ TDs.

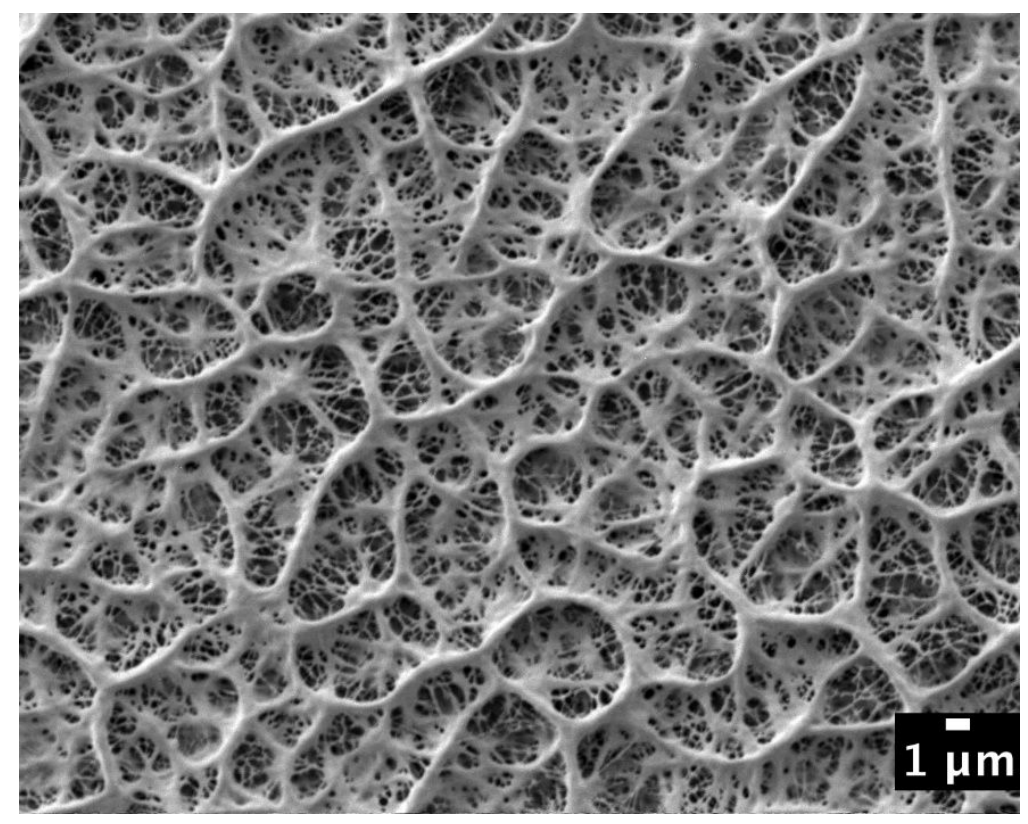

Figure S3. SEM image of the allyl-TPU fiber mats from $1 \%$ allyl-TPU in 50/50 v/v DMF/THF cosolvent at $8 \mathrm{~cm}$ TD. 


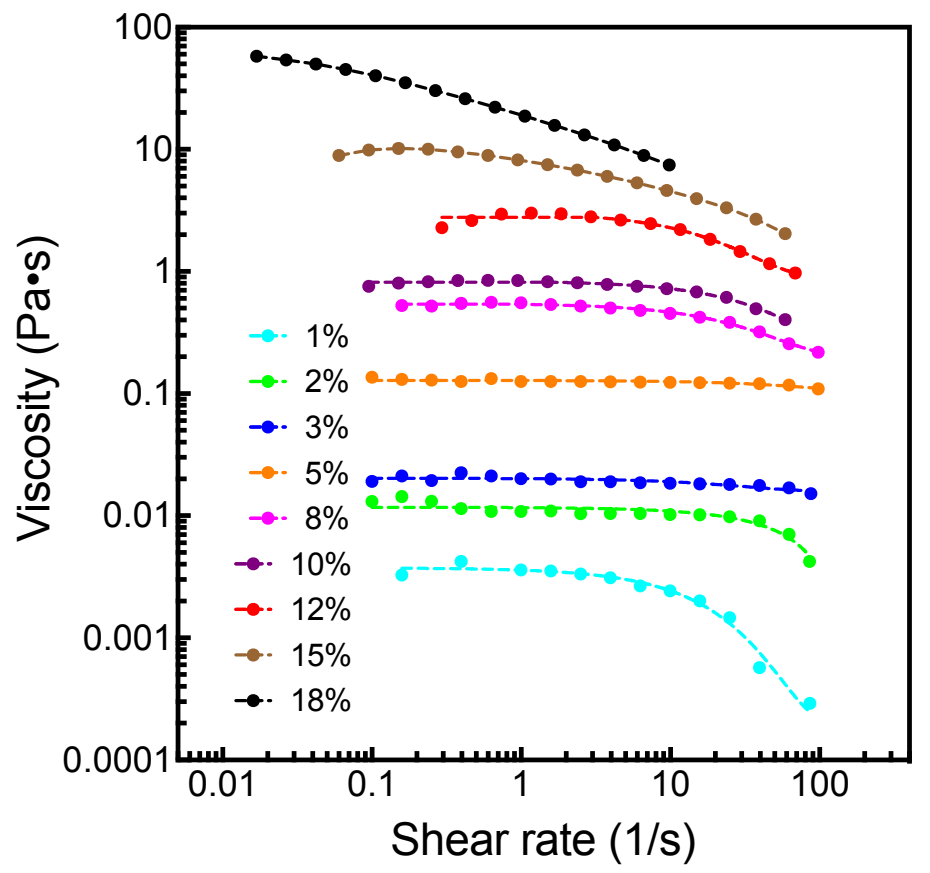

Figure S4. Viscosity plot as a function of shear rate for allyl-TPU solution in 50/50 v/v DMF/THF cosolvent at various concentrations.

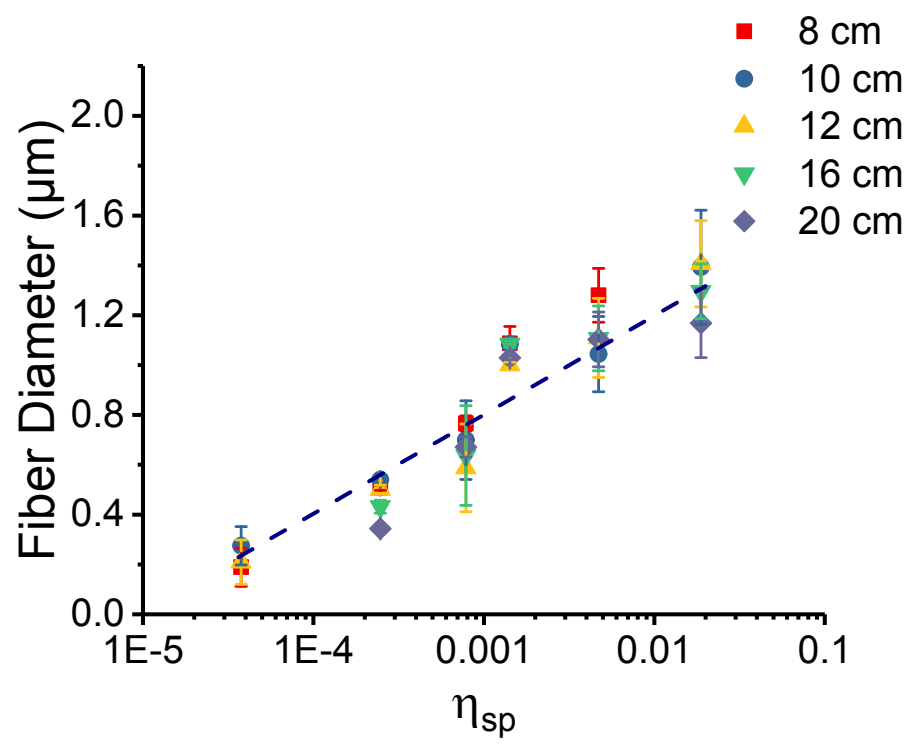

Figure S5. Dependence of fiber diameter on the specific viscosity of allyl-TPU solution. 


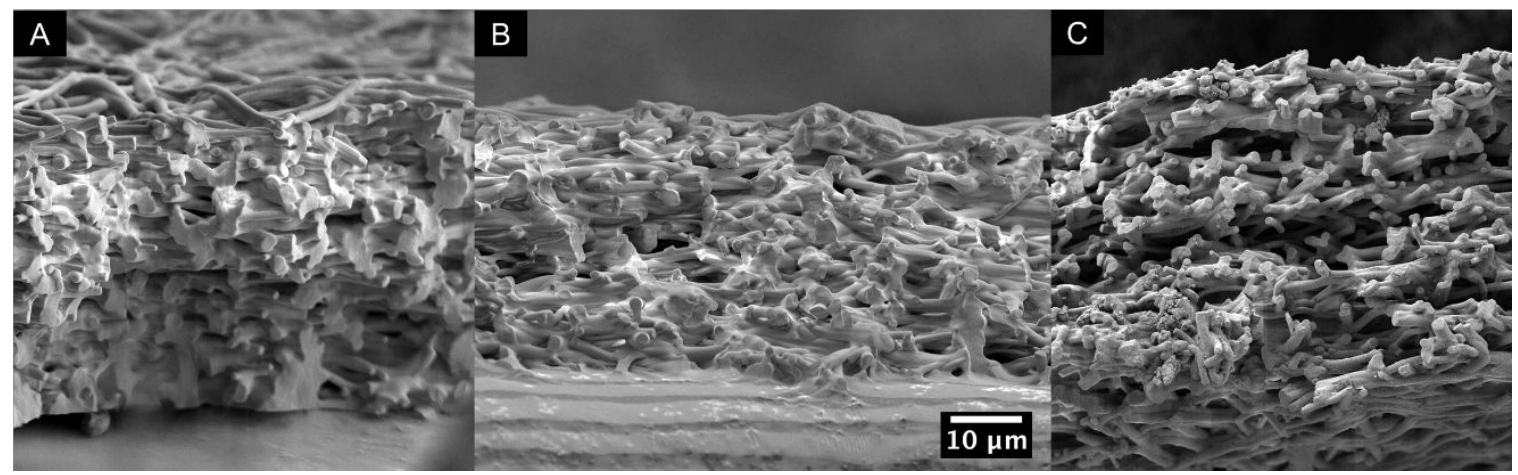

Figure S5. Cross-sectional SEM images of the allyl-TPU fiber mats electrospun at a concentration of $10 \% \mathrm{w} / \mathrm{v}$ and TDs of (A) $10 \mathrm{~cm}$, (B) $12 \mathrm{~cm}$, and (C) $16 \mathrm{~cm}$.

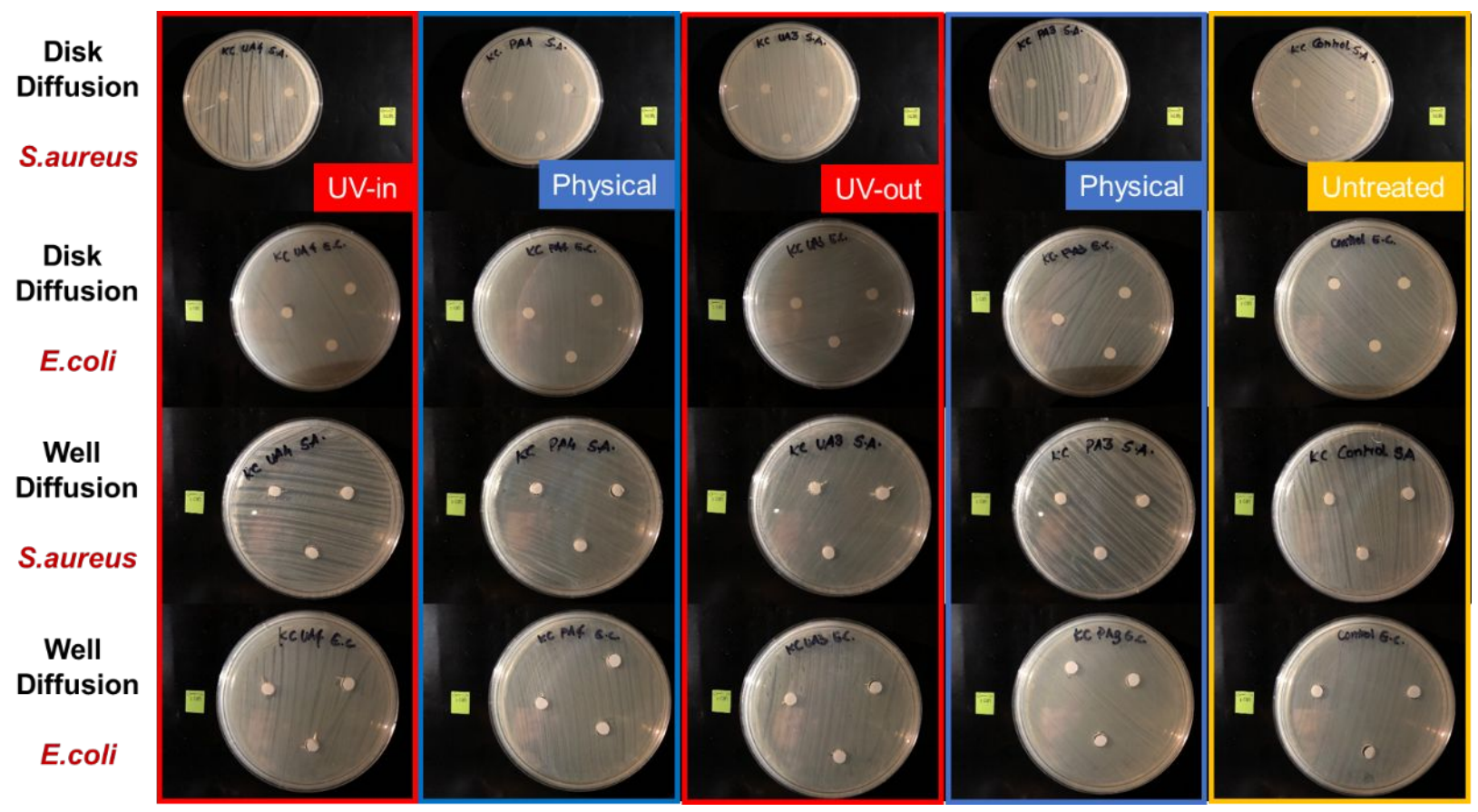

Figure S7. Additional diffusion assay images of UV-treated, physically adsorbed and untreated samples. 


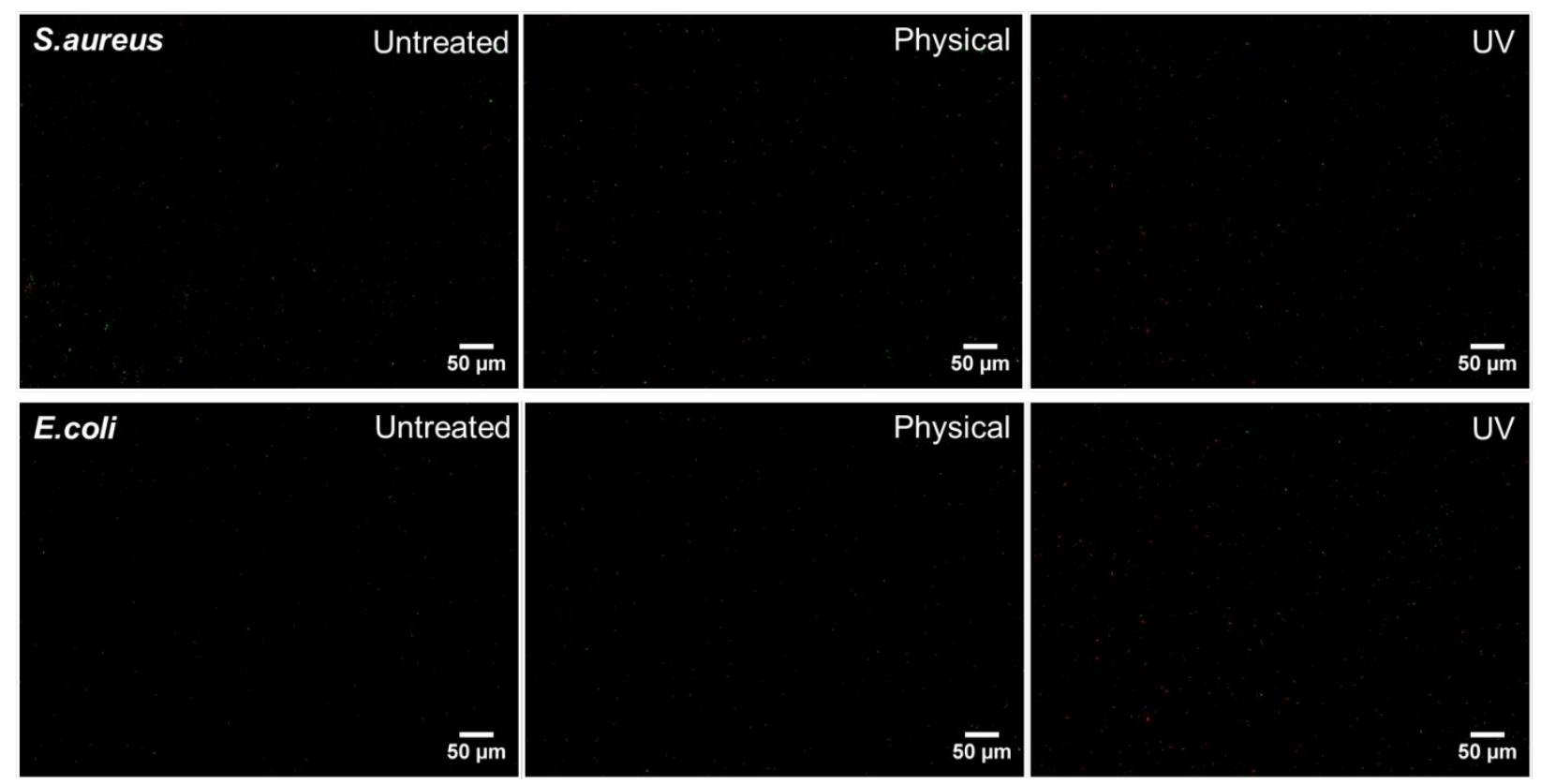

Figure S8. Images from the live/dead assay for untreated, physically adsorbed and UV-treated allyl-TPU fiber mats after in contact with S. aureus (top) and E. coli (bottom) for 15 min. 
Table S1. Summary of the polyurethane copolymers with allyl side groups.

\begin{tabular}{ccccc}
\hline & $\boldsymbol{M}_{\mathbf{n}}$ & $\boldsymbol{M}_{\mathbf{W}}$ & $\boldsymbol{M}_{\mathbf{Z}}$ & $\oplus_{\mathbf{M}}$ \\
\hline Batch 1 & 77,885 & 293,153 & 968,951 & 3.8 \\
Batch 2 & 63,765 & 186,612 & 505,617 & 2.9 \\
Batch 3 & 31,427 & 70,482 & 134,782 & 2.2 \\
\hline
\end{tabular}

Table S2. Summary of electrospun TPU fiber diameters derived at different concentrations and TDs.

\begin{tabular}{|c|c|c|c|c|c|}
\hline $\begin{array}{c}\text { Solution } \\
\text { Concentration } \\
(\% \mathrm{w} / \mathrm{v})\end{array}$ & TD (cm) & $\begin{array}{c}\text { Fiber } \\
\text { Diameter } \\
(\mu \mathrm{m})\end{array}$ & $\begin{array}{c}\text { Relative } \\
\text { Standard } \\
\text { Deviation } \\
\text { (RSD) }\end{array}$ & $\begin{array}{l}\text { Applied } \\
\text { Voltage }\end{array}$ & $\begin{array}{c}\text { Needle } \\
\text { Inner } \\
\text { Diameter }\end{array}$ \\
\hline \multirow{5}{*}{5} & 8 & $0.51 \pm 0.079$ & 0.16 & & \\
\hline & 10 & $0.54 \pm 0.211$ & 0.39 & & \\
\hline & 12 & $0.50 \pm 0.143$ & 0.29 & & \\
\hline & 16 & $0.43 \pm 0.097$ & 0.22 & & \\
\hline & 20 & $0.34 \pm 0.029$ & 0.08 & & \\
\hline \multirow{5}{*}{8} & 8 & $0.77 \pm 0.222$ & 0.29 & & \\
\hline & 10 & $0.70 \pm 0.069$ & 0.10 & & \\
\hline & 12 & $0.59 \pm 0.106$ & 0.18 & & \\
\hline & 16 & $0.64 \pm 0.096$ & 0.15 & & \\
\hline & 20 & $0.67 \pm 0.149$ & 0.22 & & \\
\hline \multirow{5}{*}{10} & 8 & $1.09 \pm 0.061$ & 0.06 & & \\
\hline & 10 & $1.08 \pm 0.145$ & 0.13 & & \\
\hline & 12 & $1.00 \pm 0.146$ & 0.14 & $8 \mathrm{kV}$ & $0.381 \mathrm{~mm}$ \\
\hline & 16 & $1.08 \pm 0.152$ & 0.14 & & \\
\hline & 20 & $1.03 \pm 0.120$ & 0.12 & & \\
\hline \multirow{4}{*}{12} & 8 & $1.28 \pm 0.108$ & 0.08 & & \\
\hline & 10 & $1.04 \pm 0.151$ & 0.14 & & \\
\hline & 12 & $1.11 \pm 0.159$ & 0.14 & & \\
\hline & 16 & $1.11 \pm 0.147$ & 0.13 & & \\
\hline
\end{tabular}




\begin{tabular}{cccc}
\hline & 20 & $1.10 \pm 0.124$ & 0.11 \\
\hline \multirow{2}{*}{15} & 8 & - & - \\
& 10 & $1.39 \pm 0.229$ & 0.16 \\
& 12 & $1.40 \pm 0.173$ & 0.17 \\
& 16 & $1.30 \pm 0.110$ & 0.11 \\
& 20 & $1.30 \pm 0.138$ & 0.12 \\
\hline
\end{tabular}

Table S3. Mechanical properties of the allyl-TPU fiber mats electrospun at a concentration of $10 \%$ $\mathrm{w} / \mathrm{v}$ and TDs of $10 \mathrm{~cm}, 12 \mathrm{~cm}$, and $16 \mathrm{~cm}$.

\begin{tabular}{cccc}
\hline TD $(\mathbf{c m})$ & $\begin{array}{c}\text { Elongation at break } \\
(\%)\end{array}$ & $\begin{array}{c}\text { Stress at break } \\
(\mathbf{M P a})\end{array}$ & $\begin{array}{c}\text { Young 's } \\
\text { modulus (MPa) }\end{array}$ \\
\hline $\mathbf{1 0}$ & $6.08 \pm 0.26$ & $51.24 \pm 0.96$ & $21.26 \pm 0.89$ \\
$\mathbf{1 2}$ & $5.36 \pm 0.08$ & $27.45 \pm 5.36$ & $11.85 \pm 1.82$ \\
$\mathbf{1 6}$ & $4.86 \pm 0.09$ & $19.97 \pm 3.63$ & $9.56 \pm 1.40$ \\
\hline
\end{tabular}

Table S4. Quantification of rhodamine-SH and QAC-SH present on UV treated and physically adsorbed allyl-TPU fiber mats as determined by fluorescence spectroscopy and XPS measurements, respectively.

\begin{tabular}{|c|c|c|c|c|c|}
\hline \multirow[t]{2}{*}{ Thiol } & $\begin{array}{c}\text { Dipping } \\
\text { Time } \\
\text { (min) }\end{array}$ & $\begin{array}{c}U V \\
\text { Treatment } \\
\text { (min) }\end{array}$ & $\begin{array}{c}\text { Physical } \\
\text { Adsorption }\end{array}$ & $\begin{array}{c}\text { UV Treated in } \\
\text { Thiol Bath }\end{array}$ & $\begin{array}{c}\text { UV Treated out } \\
\text { of Thiol Bath }\end{array}$ \\
\hline & \multicolumn{5}{|c|}{ Fluorescence Data $\left(10^{-7} \mathrm{~mol} / \mathrm{cm}^{2}\right)$} \\
\hline \multirow{4}{*}{$\begin{array}{c}\text { Rhodamine } \\
\text {-SH }\end{array}$} & 1 & 1 & $0.80 \pm 0.01$ & - & $0.93 \pm 0.01$ \\
\hline & 10 & 10 & $1.17 \pm 0.01$ & $1.30 \pm 0.06$ & $1.35 \pm 0.08$ \\
\hline & 30 & 30 & $1.49 \pm 0.04$ & $3.05 \pm 0.19$ & $3.58 \pm 0.71$ \\
\hline & \multicolumn{5}{|c|}{ XPS Data $\left(\% \mathrm{NR}_{4}{ }^{+}\right.$relative to $\left.\mathrm{N}\right)$} \\
\hline \multirow{2}{*}{ QAC-SH } & 5 & 30 & - & 8.64 & 10.78 \\
\hline & 30 & 30 & - & $17.36 \pm 1.36$ & $15.62 \pm 5.16$ \\
\hline
\end{tabular}


Table S5. Contact-killing assay (adapted from ISO 22196) results of UV-treated, physically adsorbed and untreated allyl-TPU fiber mats in contact with $E$. coli and $S$. aureus suspensions (ca. $10^{5} \mathrm{CFU} / \mathrm{mL}$ ) for $24 \mathrm{~h}$.

\section{Mean CFU/Sample Recovered ${ }^{\text {a }}$}

\begin{tabular}{ccc}
\hline \hline Sample & E. coli & S. aureus \\
\hline Glass coverslip & $5.2( \pm 2.50) \times 10^{3}$ & $9.50( \pm 0.49) \times 10^{3}$ \\
Untreated & $1.40( \pm 0.92) \times 10^{3}$ & $2.25( \pm 1.96) \times 10^{3}$ \\
\hline UV-in & $0.20( \pm 0.35) \times 10^{3}$ & $0.00 \pm 0.00$ \\
(UV treated when samples in thiol bath) & & $0.36( \pm 0.62) \times 10^{3}$ \\
\hline Physical & $0.60( \pm 0.00) \times 10^{3}$ & \\
\hline UV-out & $0.00 \pm 0.00$ & $0.20( \pm 0.35) \times 10^{3}$ \\
Physical & $1.20( \pm 0.6) \times 10^{3}$ & $2.00( \pm 1.73) \times 10^{3}$
\end{tabular}

${ }^{a}$ Mean CFU/sample data were determined by plating counting, performed in triplicate $(n=3)$.

Table S6. Comparing mechanical properties of fiber mats before and after functionalization

\begin{tabular}{cc}
\hline Sample & Young 's modulus (MPa) \\
\hline Unfunctionalized Fiber mat & $36.38 \pm 0.54$ \\
Functionalized Fiber mat & $37.58 \pm 1.93$ \\
\hline
\end{tabular}




\section{Section S1. Derivation of Equation (1).}

For a single fiber, surface area can be calculated using,

$$
A=\pi d \times L
$$

with $\mathrm{d}$ represents the mean fiber diameter determined from SEM images of fiber mats and $\mathrm{L}$ represents the length of one single fiber.

In addition, volume can be calculated using

$$
V=\pi \frac{d^{2}}{2} \times L
$$

Therefore, surface to volume ratio can be calculated using

$$
\frac{A}{V}=\frac{4}{d}
$$

